\title{
Industry-linked Projects and Research-informed-and-enriched Curriculum for Sustainable Student Employability Metrics
}

\author{
Sunday Cookey Ekpo \\ Manchester Metropolitan University
}

\begin{abstract}
This paper presents inclusive industry-linked projects and research-informed-and-enriched curriculum for sustainable improved student educational metrics. A research project questionnaire was designed for data gathering besides the use of the researcher's historical engineering curriculum teaching and research project supervision data. Monte Carlo simulations, t-test analysis and probability density functions modelling were implemented to obtain future-predicting reliable outcomes. The results of the analyses show that the student engagement improved by over $50 \% ; 100 \%$ of the students who experienced industry-linked pedagogy with formative assessment feedback and feedforward achieved a distinction grade. $100 \%$ of taught and supervised students gained employment into the industry; and/or embarked on further education (MSc and PhD).
\end{abstract}

Keywords: engagement, formative assessment, intervention strategies, progression, retention

\section{INTRODUCTION}

The traditional methods of teaching engineering units in the Department of Engineering (DoE), Manchester Metropolitan University have been radically transformed in the last four years. The hitherto predominantly conceptual and limited application-based course contents and delivery activities have been enriched with live projects and post-unit delivery formative assessments. This approach is aimed at enhancing the professionalism of the students besides enabling the teachers and students to appreciate their respective indispensable adjustments of their instructional activities and learning tactics. Furthermore, the DoE embraces an industry and research-informed-and-enriched teaching model where a discipline-based research should explicitly relate to the curriculum experienced by the students in those disciplines. Hence, the curriculum and the assessment enable the students to generate work outputs that are close to the research techniques/processes within that discipline (Fernando. \& Ekpo, 2015). The formative assessment was designed to commence soon after every unit topic delivery to enable the students self-regulate their learning and offer the teachers a feedback mechanism to adjust their current and future instructional materials and activities (Nicol \& MacFarlane-Dick, 2005).

The findings arising from this research project was aimed at helping to contribute towards the accomplishment of the principles of the strategy for learning, teaching and assessment of the Manchester Metropolitan University (including excellent learning environment and outstanding student experience; flexible; enterprising and internationalized curriculum; constructively-aligned assessment; student progression, confidence and success; quality-driven responsive programs; and professional development of staff members as engaging lifelong learners. 
Students' progress prediction and implementation of appropriate intervention strategies cannot be overemphasized. These are linked to the constructively-aligned course design and unit delivery and assessment with recourse to an appropriate standard framework. Moreover, other key themes of this research involved industry-linked engineering students' projects, formative assessment, feedback and feedforward (Nicol \& MacFarlane-Dick, 2005). The project element consisted of the actual research activity undertaken by the individual students. The formative assessment was based on the graded institutional project presentations, project review and technical report writing. A formative feedback accompanied each mock formative assessment element; it also formed an ongoing recommendation(s) and/or suggestion(s) following individual student's and research team's project meetings and practical demonstration of achieved project milestones and/or deliverables.

This paper presents a research study on industry-linked engineering pedagogy spanning researchinformed-and-enriched (RIE) learning and teaching; evidence-based RIE project supervision; and evidence-based RIE curriculum design. The formative assessment, feedback and feedforward (FAFF) comprise a productive integrated teaching-supervision craft practice tool. The FAFF tool can help to enhance the student's grades and exit award; professional career progress; entrepreneurship; employment; and employability. Advanced statistical techniques (including $t$-test and probability density functions) and simulations tools (including Monte Carlo analysis) were studied and implemented in this research project. The context of the study focused on the teaching and supervision of engineering projects that are implemented by engineering students with recourse to the industry-linked research contents; learning new technologies/applications; and employability.

This paper is organized as follows. Section two presents a novel industry-linked engineering pedagogy model that embraces research-informed-and-enriched contents. This section starts with a review of formative assessment, feedback and feedforward; and student experience and engagement. The research methodology and methods are covered in section two. The pertinent data collection, representation, analysis, results and discussion are stated in section three. Section four concludes this paper.

\section{INDUSTRY-LINKED ENGINEERING PEDAGOGY}

\section{Introduction}

Student experience can only be measured based on the acceptable standard assessment of learning and teaching activities carried out and the objective feedback and feedforward from the learners. Hence, these concepts are interrelated and supply the information that enable(s) the situational judicious adjustment for achieving the appropriate unit and graduate learning outcomes and the University's standard descriptors. Reasonable learning and teaching adjustments techniques without a corresponding educational metric driver is akin to a moving vehicle without a defined destination. To attain an acceptable seamless sustainable employability metric, there is a need to bring the industry to the academe. This requires a radical change to the conventional pedagogy curriculum design to allow for inclusive industry-linked contents.

\section{Formative Assessment, Feedback and Feedforward}

Students as self-regulated learners implies that they take responsibility for their own learning in a proactive rather than reactive manner to generate and use feedback. This understanding profoundly drives the way in which teachers and/or tutors support learning, provide feedbacks and organize unit topics, contents, deliveries and assessments. The purpose of a formative assessment is to trigger feedback on student's performance for an improved and accelerated learning. In higher education (HE), it is reasoned that formative assessment, feedback and feedforward should form an integral part of student empowerment for self-regulated learning. The concept of self-regulation defines the way students adapt their critical thinking, behavior and motivation to fulfil their expected learning outcomes. From available literature, self-regulated students are effective learners with learning attributes that demonstrate more sustainability, confidence, resourcefulness and higher achievement (Pintrich \& Zusho, 2002). Moreover, 
formative assessment and feedback have been identified as processes that can enhance the development of self-regulation in students and provoke evidence of achievement (Popham, 2008). Elicited evidence of student achievement must be interpreted and utilised by the pedagogic stakeholders to make informed reasonable adjustments in progressing instructional resources. A focus of this paper is to investigate the role of industry-linked research-informed and-enriched pedagogy and formative assessment as an integrated tool to enable the teacher to predict students' progress, identify difficult unit topics and prepare the appropriate intervention strategies (Black \& William, 2009).

Formative assessment has been defined as a "planned process in which assessment-elicited evidence of students' status is used by teachers to adjust their ongoing instructional procedures or by students to adjust their current learning tactics" (Popham, 2008). The fundamental distinguishable feasible functions of a formative assessment can be summarized in the form of levels of attainment as follows:

a) Level 1: teachers use formative assessment to accumulate evidence to adjust their current and future instructional materials and activities;

b) Level 2: students use formative assessment findings to adjust their own learning skills;

c) Level 3: a radical change in the atmosphere of the classroom where students generate evidence from which students and teachers can adjust their LT activities; and

d) Level 4: a pan-school adoption of formative assessment levels and/or formats through the utilisation of professional development and teacher learning networks/communities.

Formative assessment is used by teachers and students to provide an assessment-based feedback to teachers and students. The feedback functions by helping teachers and students to make adjustments (Argos \& Ezquerr, 2014) in their respective learning and teaching activities that will enhance the students' achievement of intended curricular learning outcomes and/or objectives.

This paper presents a developed model of learning, teaching and assessment (LTA) that enhances the effectiveness of engineering units delivery, learning and assessment (for student's progress prediction, appropriate intervention strategies and identification of the relative difficulty of the topics covered in the unit) based on the research findings from an existing academic practice. Novel blended learning is embraced (Garrison, \& Kanuka, 2004) and integrated.

\section{Student Experience and Engagement}

There are two main levels of formative assessment, feedback and feedforward (Popham, 2008) that can be applied in a curriculum delivery to achieve a sustainable student experience and engagement (Moses, 2008). These include:

a) Level 1: Teacher-focused operation

a. Step 1: Identifying adjustment occasions;

b. Step 2: Selecting assessments;

c. Step 3: Establishing adjustment triggers; and

d. Step 4: Making instructional adjustments.

b) Level 2: Student-focused operation

a. Step 1: Consider adjustment occasions: The student considers teacher recommendations regarding when during an instructional sequence learning tactic adjustment decisions might best be made;

b. Step 2: Consider assessments: The student considers teacher-identified potential assessment procedures that can contribute to learning tactic adjustment decisions;

c. Step 3: Consider adjustment triggers: The student considers teacher-identified potential levels of student performance that indicate learning tactic adjustments are warranted; and

d. Step 4: Consider and adjust learning tactics: The student considers teacher-proposed learning tactic adjustments to improve the effectiveness of those tactics and decides on the adjustment to make.

In the context of this research, the teacher- and student-focused operations involved their engagement with the teaching and learning materials and the formative and summative assessments. Both the teacher 
and the learners can be viewed to be generating information for each other in a cyclical manner. The teacher uses the assessments to identify the gaps and needs in the Unit contents and delivery. On the other hand, the students carry out a self-assessment of how much relevant knowledge they have accumulated to gain their expected grade classification and be employable.

The next subsection introduces the developed and implemented industry-linked RIE engineering pedagogy. This modern engineering learning and teaching philosophy can be adopted and adapted for all units and/or subjects taught at any educational level.

\section{Industry-linked Engineering Pedagogy}

Excellent student experience is related to retention, engagement, progression and achievement. A student project constitutes the largest single piece of employability-centric work the individual students will carry out during their degree course. Most students see their University projects only as a unit to be fulfilled for their degree attainment and think less of their post-University professional and academic career ambitions.

Many manufacturing and service industries are experiencing a growing shortage of engineering expertise in niche technologies that drive the global economy ((Moses, 1984). Companies are finding it difficult to seamlessly integrate graduate engineers into their operations to replace retirees. The obvious reason is that the graduate engineers lack specific application experience to handle the existing and emerging complex technologies that support business operations (Emerson, 2020). Currently, up to $60 \%$ of tenured engineers are retiring and companies have identified this trend to increase in the nearest future (Emerson, 2020). Fewer hirable engineers are available today due to new employees potentially having the technical know-how, but lacking the experience.

The leading course of action by companies to address the problem of lack of competent engineers involves in-house training and internships to students. This is aimed at helping to educate up-andcoming/future engineers through the industry-relevant hands-on experience they will need (Emerson, 2020).

The lack of hirable industry-relevant graduate engineers is a global challenge occasioned by an obsolete engineering pedagogy curriculum that is detached from the rudiments of modern industries. This has a ripple effect on the HE institutions in terms of poor educational metrics (including employability). To obviate this expanding worldwide industry employability problem, a novel industry-linked researchinformed-and-enriched engineering pedagogy has been developed and implemented.

The pertinent question is thus: "why do we need industry-linked engineering pedagogy?" To answer this question, it is vital to consider why HE institutions record poor employability metrics and the companies experience a growing shortage of competent workforce. Hence, the following constitute the core reasons for adopting an industry-linked RIE pedagogy, viz:

a) An educational metrics root cause analysis opportunity creation;

b) A systematic approach to student experience lifecycle reflection;

c) Focus is shifted from individual learners and teachers onto the educational system:

a. to help build an open and fair culture.

d) Increases an awareness of modern educational metrics and curriculum design issues; and

e) Allows for engagement of both staff members and students in the inclusive and proactive value-driven learning and teaching process. 
FIGURE 1

TEACHING-BASED RIE MODEL OF REFLECTION

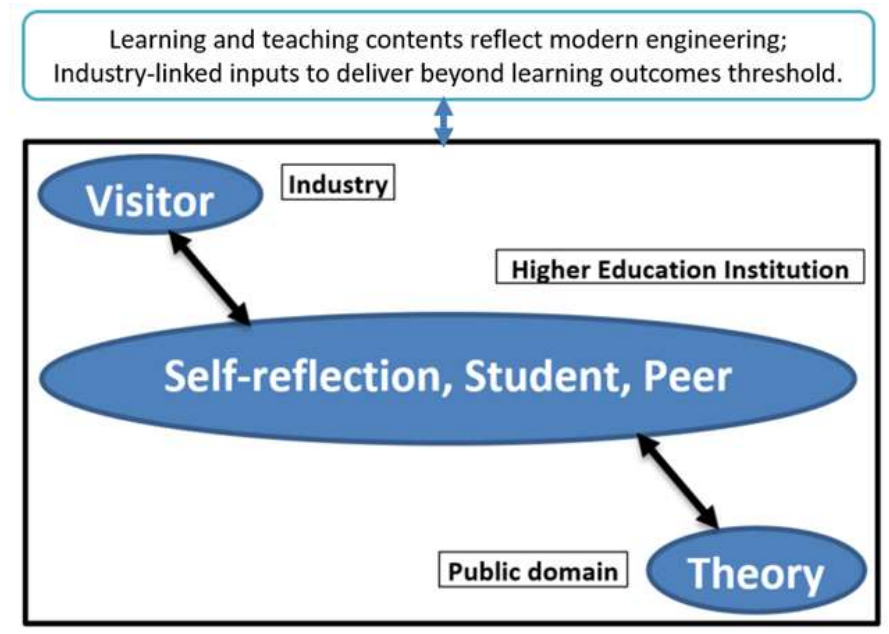

FIGURE 2

PROJECT-BASED RIE MODEL OF REFLECTION

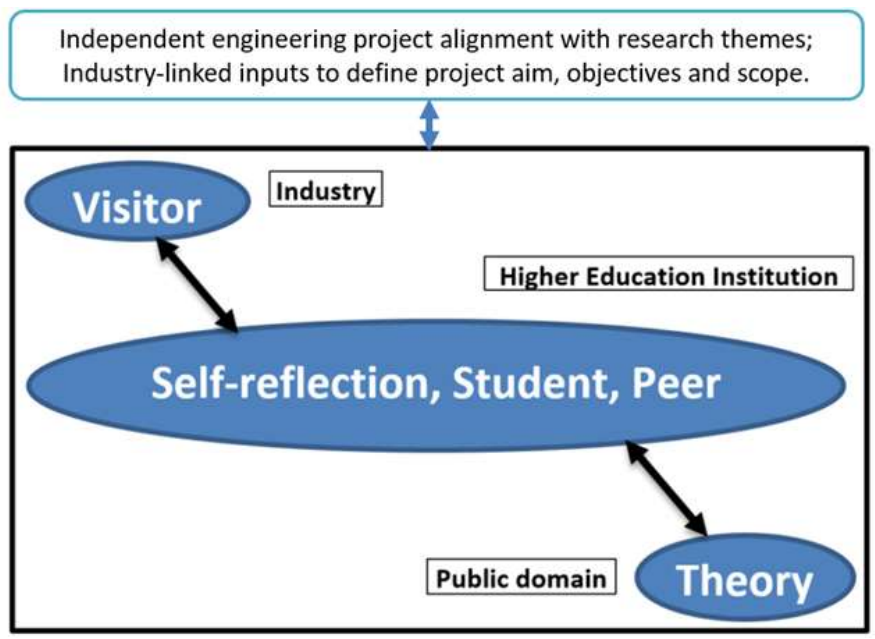

As a reflective process, the two main types of industry-linked RIE pedagogy that incorporate curriculum contents development are teaching-based RIE model of reflection (Figure 1); and projectbased RIE model of reflection (Figure 2) (Ekpo, 2020).

For a case study Unit design and assessment, the teaching-based RIE pedagogy utilizes industry resources to ensure that:

a) Unit is constructively-aligned with assessments;

b) RIE lecture, workshop and tutorial sessions contain modern industry-relevant engineering principles and hands-on contents;

c) Examination and coursework reflect modern engineering;

d) Industrial partners co-deliver specialist contents; and

e) Accreditation body's requirements (e.g., the Institution of Engineering and Technology's Accreditation of Higher Education Programmes learning outcomes and Chartered Engineering competences) are emphasised. 


\section{RESEARCH METHODOLOGY AND METHODS}

\section{Introduction}

This section presents the methodology, methods and data analysis tools used for this research. This research project was carried out using the Microsoft Excel software package for data presentation and statistical analysis; and the MatLab software package for advanced data simulations and visualizations.

\section{Methodology}

Appropriate literature investigations were carried out on employability metric; and formative assessment, feedback and feedforward to underpin the theory behind this research study and identify the gap in the knowledge that this work would fill. The context of the study focused more on the supervision of engineering projects that are implemented by engineering students with recourse to the industry-linked research contents; learning new technologies/applications; and employability. Given the limited sample size of 10 undergraduate and 1 postgraduate students, the relevant statistical techniques (including mean, standard deviation, $t$-test and probability density functions) and advanced simulations tools (including Monte Carlo analysis) were studied and implemented in this research project.

A hybrid research methodology involving quantitative and qualitative research techniques were utilized in this research project. For the quantitative data analysis, mainly parametric (interval and/or ratio) data were explored. Hence, appropriate descriptive and significance testing techniques were applied to generalize the relationships and characteristics that exist amongst the students that were taught and supervised using the industry-linked RIE pedagogy model.

For this research project, the pertinent hypothesis comprises thus:

- Formative assessment and feedback enhance student engagement and achievement and/or

- There is a significant correlation between formative assessment and feedback and student's performance. This hypothesis will consider the use of formative assessment (including mock project presentations) and supervisor's feedback to improve student's project engagement and grade.

The data used for this study represent a sample of a population. Hence, advanced statistical techniques (such as $t$-test) and Monte Carlo simulations were carried out to investigate the above hypotheses in a small sample of engineering students at one University.

Descriptive (such as frequency histograms and measures of central tendency (mean) and dispersion (standard deviation)) and analytical/inferential (test of significance including $t$-test (one sample) statistical techniques were carried out to investigate the above hypothesis.

This research methodology(s) was adopted to enable a holistic understanding of the present and future impacts of the study.

\section{Monte Carlo Simulations}

If the score by each student, $X$, is the only random variable and $X$ has, for example, a lognormal distribution, then the student's response rate, $Y$, will also have a lognormal distribution. However, if several variables are random, then the analysis becomes much more complicated. In this dissertation report, a single random variable (score), $X$, exhibits different distributions for different independent criteria and hence, each case study of the students' responses is mutually exclusive and complicated.

A way of handling the complexity of the analysis of several random variables and/or several distributions from a single random variable is by using the sampling technique as follows:

a) Assume or determine a distribution function to represent the input variable(s);

b) Sample each variable independently;

c) Calculate the students' response from the estimating relationship; and

d) Repeat the process many times to obtain a set of outputs or students' response distribution.

Given the probability that each input random variable (score) will take up a certain value, the students' response can be estimated accurately from the output distribution following many iterations. The above is called Monte Carlo simulation. For the presented case study student research project 
implementation and experience response, the score, $X$, is assumed to be a uniformly distributed random variable. This means it has an equal probability of lying in some interval between $X 1$ and $X 2$ and a zero probability outside it. Table 1 shows the minimum and maximum values of $X$.

\section{TABLE 1}

\section{VALUES OF RANDOM VARIABLE SCORE, $X$}

\begin{tabular}{|c|c|c|}
\hline able $^{\text {Vari }}$ & $\begin{array}{c}X 1 \\
\text { (minimum } \\
\text { value) }\end{array}$ & $\begin{array}{c}X 2 \\
\text { (maximum } \\
\text { value) }\end{array}$ \\
\hline \begin{tabular}{l}
\multicolumn{1}{c}{ Scor } \\
$\mathrm{e}, X$
\end{tabular} & 4 & 5 \\
\hline
\end{tabular}

The Monte Carlos analysis depends on the determination of the appropriate estimating function equation for the sample data. For the purpose of deriving the estimating relationships of the sample data using linear and non-linear programming techniques, the following conventions have been adopted in this research project.

a) Y1: Research Team Experience;

b) Y2: Engineering Team Experience;

c) Y3: Usefulness of Mock Project Presentation;

d) Y4: Usefulness of your supervisor's feedback towards your research project engagement;

e) Y5: Usefulness of working with professional engineers during research project implementation; and

f) Y6: Usefulness of project supervisor's feedback towards project engagement.

The corresponding estimating relationships based on the student project data are summarized as follows:

$Y 1=-0.7576 X^{3}+7.4675 X^{2}-9.9567 X+1.8182$

$R_{1}{ }^{2}=0.9081$ (where $R_{i}^{2}(i=1,2, \ldots)$ is the corresponding coefficient of determination for a non-linear programming function).

$Y 2=Y 2_{\mathrm{q}}+Y 2_{1}=0.5\left(-1.2987 X^{2}+22.3377 X-12.7272\right)$

The corresponding $R_{2}^{2}=0.9416$.

$Y 3=3.0303 X^{3}-19.481 X^{2}+41.126 X-25.455$

The corresponding $R_{3}^{2}=0.9885$.

$Y 4=-2.2727 X^{3}+21.753 X^{2}-48.701 X+29.091$

The corresponding $R_{4}^{2}=0.9993$.

$Y 5=3 \mathrm{E}-14 X^{3}-1.2987 X^{2}+16.883 X-16.364$

The corresponding $R_{5}^{2}=0.9524$

$Y 6=-1.5152 X^{3}+11.688 X^{2}-14.069 X+1.8182$

The corresponding $R_{6}{ }^{2}=0.7823$

64 Journal of Higher Education Theory and Practice Vol. 20(3) 2020 


\section{DATA COLLECTION, REPRESENTATION AND ANALYSIS}

\section{Introduction}

The section details the data collection method, representation and analysis that were carried out. It also contains the results of the data analysis and the pertinent discussion arising for the research findings.

\section{Data Collection}

The pertinent data collection enumeration procedure for this project includes:

- A review of the generic and discipline-specific requirements for final-year undergraduate engineering projects;

- An investigation of the assessment frameworks and/or theories (with a particular focus on formative assessment and feedback) for final-year undergraduate engineering projects;

- An identification of the factors that influence and drive student engagement in a final-year engineering project;

- Obtaining qualitative and quantitative data on the final-year undergraduate engineering projects progress over an academic session;

- Using statistical techniques to analyse the final-year engineering project student data following a FAFF;

- Establishing the impact of formative assessment and feedback on student engagement (and achievement) from the author's practice; and

- Recommending a final-year engineering project supervision model for effective student engagement and achievement.

The adopted pertinent data collection methods for this research project involved:

- Existing/historical data analysis (from past supervision(s)) involving at least three mock presentations and peer-assessments;

- Emerging data from assessments (as part of an ongoing supervision); and

- Questionnaire.

The above methods were used to obtain research data from the students who were taught and supervised by the author. Moreover, the students were given a research project progress timeline form to complete per week to assess their engagement in the project. This research methodology(s) was adopted to enable a holistic understanding of the present and future impacts of the study. A research project questionnaire was designed for a project timeline data gathering besides the use of the researcher's historical supervision data.

\section{Data Representation}

Table 2 shows the descriptive statistics (including mean and standard deviation) and positive response (including students who gave a score of 4 and 5) of the students' project experience. 
TABLE 2

DESCRIPTIVE STATISTICS OF THE STUDENTS' PROJECTEXPERIENCE

\begin{tabular}{lccc}
\hline \multicolumn{1}{c}{ Project experience ID } & \multicolumn{2}{c}{ Descriptive statistics } & \multirow{2}{*}{ Positive response (\%) } \\
\cline { 2 - 3 } & Mean & SD & \\
\hline PE1 (Research Team Experience) & 4.18 & 0.87 & 80.4 \\
PE2 (Engineering Team Experience) & 3.73 & 1.19 & 68.3 \\
PE3 (Usefulness of Mock Project Presentation) & 4.64 & 0.67 & 94.1 \\
PE4 (Usefulness of your supervisor's feedback & 4.27 & 0.79 & 87.2 \\
towards your research project) & & & \\
PE5 (Usefulness of working with professional & 3.91 & 1.04 & 74.4 \\
engineers during research project implementation) & & & \\
PE6 (Usefulness of project supervisor's feedback & 4.00 & 0.89 & 72.2 \\
towards your research project engagement) & & & \\
\hline
\end{tabular}

TABLE 3

FACTORS MOTIVATING STUDENTS'CHOICE OF SUPERVISOR AND/OR THEIR RESEARCH PROJECT

\begin{tabular}{|c|c|c|c|c|c|c|c|c|c|c|c|c|}
\hline \multirow[t]{2}{*}{ Supervisor \& Project Choice Factor } & \multicolumn{11}{|c|}{ Respondents' Response } & \multirow{2}{*}{$\begin{array}{l}\text { Response } \\
(\%)\end{array}$} \\
\hline & R1 & R2 & R3 & R4 & R5 & R6 & R7 & R8 & R9 & R10 & R11 & \\
\hline Industrial link and sponsorship & $\mathrm{Y}$ & & & & $\mathrm{Y}$ & & $\mathrm{Y}$ & & & & $\mathrm{Y}$ & 36.36 \\
\hline $\begin{array}{l}\text { Opportunities to learn new technology and } \\
\text { applications }\end{array}$ & $\mathrm{Y}$ & $\mathrm{Y}$ & $\mathrm{Y}$ & $\mathrm{Y}$ & & $\mathrm{Y}$ & $\mathrm{Y}$ & $\mathrm{Y}$ & $\mathrm{Y}$ & $\mathrm{Y}$ & $\mathrm{Y}$ & 90.91 \\
\hline The profile of the research team & & & & $\mathrm{Y}$ & $\mathrm{Y}$ & & & $\mathrm{Y}$ & $\mathrm{Y}$ & & & 36.36 \\
\hline Availability and support of your supervisor & & & $\mathrm{Y}$ & $\mathrm{Y}$ & & $\mathrm{Y}$ & $\mathrm{Y}$ & $\mathrm{Y}$ & & & $\mathrm{Y}$ & 54.55 \\
\hline Rigour and technical depth of the project & & & $\mathrm{Y}$ & $\mathrm{Y}$ & $\mathrm{Y}$ & & $\mathrm{Y}$ & & & & $\mathrm{Y}$ & 45.45 \\
\hline Future career prospects and professional practice & & $\mathrm{Y}$ & & $\mathrm{Y}$ & $\mathrm{Y}$ & & $\mathrm{Y}$ & & & $\mathrm{Y}$ & $\mathrm{Y}$ & 54.55 \\
\hline $\begin{array}{l}\text { Training offered by the industrial partner(s) and } \\
\text { project sponsor(s) }\end{array}$ & & & & $\mathrm{Y}$ & & & $\mathrm{Y}$ & & & & & 18.18 \\
\hline Other (please, state them): & & & & & & & & & & & & 0.0 \\
\hline
\end{tabular}

\section{Data Analysis, Results and Discussion}

From the collected samples, the mean of the Usefulness of mock project presentation is 4.63636 and the mean of the Usefulness of supervisor's feedback towards a research project engagement is 4 . Since there is a difference in the means of the two samples, the statistical significance of this difference is going to be calculated using the paired t-test technique. The hypothesized mean difference is 0 . The alpha (p-) value is 0.05 .

The relevant statistics are the $t$-stat, $P(T<=t)$ two-tail and $t$ Critical two-tail. From Table 4 , the calculated $t$-stat is 1.8843 . This implies that these results are approximately 1.88 standard deviations from the mean. Table 4 indicates that for one-tail and two-tail tests, the respective $t$ values of 1.8125 and 2.2281 would be needed to reject the null hypothesis. As this is a two-tail test and the calculated $t$-stat is not in excess of the critical value (i.e., $t=2.2281$ ), the null hypothesis holds. Furthermore, since the statistically calculated $p$-value (i.e., $P(T \leq t)$ two-tail $=0.0889)$ is greater than alpha $(p=0.05)$, the alternative hypothesis is rejected. This implies that the there is a significant positive relationship between the supervisor's feedback and the student's project engagement. In essence, the supervision craft practices provide the enabling channels for the individual students to achieve excellent grades and exit with employable honours.

From the collected samples, the mean of the Usefulness of the supervisor's feedback is 4.2727 and the Usefulness of supervisor's feedback towards a research project engagement is 4 . Since there is a 
difference in the means of the two samples, the statistical significance of this difference is going to be calculated using the paired $t$-test technique. The hypothesized mean difference is 0 (Table 5). In Table 5, the calculated $t$-stat is 1.3988 . This implies that these results are approximately 1.40 standard deviations from the mean. Table 5 shows that for one-tail and two-tail tests, the respective $t$ values of 1.8125 and 2.2281 would be needed to reject the null hypothesis. As this is a two-tail test and the calculated $t$-stat is not in excess of the critical value (i.e., $t=2.2281$ ), the null hypothesis holds. Furthermore, since the statistically calculated $p$-value (i.e., $P(T \leq t)$ two-tail $=0.1921)$ is greater than alpha $(p=0.05)$, the alternative hypothesis is rejected. This implies that the usefulness of supervisor's feedback towards a research project engagement is as significant as the usefulness of mock project presentation. In essence, both supervision craft practices provide the enabling channels for the individual students to achieve excellent grades and exit with employable honours.

Following a combined judicious and critical analysis of the sample data using descriptive statistical techniques and data model simulations, the key research questions have been addressed. The main factors influencing the choice of a BEng/BSc final-year undergraduate and MSc postgraduate engineering projects are summarized in Table 3. The survey data reveal that "opportunities to learn new technologies and applications" (with a positive response rate of $91 \%$ ) emerges the most influencing factor. This reveals the hidden innovative drive and hunger for knowledge in our students that should be harnessed and satisfied through a holistic research-informed student project design that captures the multidisciplinary University learning environment.

TABLE 4 t-TEST: PAIRED TWO SAMPLE FOR MEANS - MOCK PRESENTATION

\begin{tabular}{lcc}
\hline & $\begin{array}{c}\text { Usefulness of mock project } \\
\text { presentation }\end{array}$ & $\begin{array}{c}\text { Usefulness of } \\
\text { Supervisor's feedback }\end{array}$ \\
\hline Mean & 4.6364 & 4 \\
Variance & 0.4545 & 0.8 \\
Observations & 11 & 11 \\
Pearson Correlation & 0 & \\
Hypothesized Mean & & \\
Difference & 0 & \\
$d f$ & 10 & \\
$t$ Stat & 1.8843 & \\
$P(T \leq \mathrm{t})$ one-tail & 0.0444 & \\
$t$ Critical one-tail & 1.8125 & \\
$P(T \leq t)$ two-tail & 0.0889 & \\
$t$ Critical two-tail & 2.2281 & \\
\hline \hline
\end{tabular}




\section{TABLE 5 \\ $t$-TEST: PAIRED TWO SAMPLE FOR MEANS - SUPERVISOR'S FEEDBACK}

\begin{tabular}{lcc}
\hline \hline & $\begin{array}{c}\text { Usefulness of } \\
\text { supervisor's feedback }\end{array}$ & $\begin{array}{c}\text { Usefulness of supervisor's } \\
\text { feedback towards research } \\
\text { project engagement }\end{array}$ \\
\hline Mean & 4.2727 & 4 \\
Variance & 0.6182 & 0.8 \\
Observations & 11 & 11 \\
Pearson Correlation & 0.7108 & \\
Hypothesized Mean Difference & 0 & \\
df & 10 & \\
$t$ Stat & 1.3988 & \\
$P(T \leq \mathrm{t})$ one-tail & 0.0961 & \\
$t$ Critical one-tail & 1.8125 & \\
$P(T \leq t)$ two-tail & 0.1921 & \\
$t$ Critical two-tail & 2.2281 & \\
\hline
\end{tabular}

The level of formative assessment and feedback that enhances a student engagement potential in an engineering project has been found to be research-informed. Learning and teaching styles in engineering education (Felder \& Silverman, 1988) are enhanced through industry-linked resources. This is reflected in the overwhelming interest of the supervised engineering project students in gaining new knowledge and learning about emerging applications (Felder, Woods, Stice \& Rugarcia, 2000). Again, the sample data reveal a positive response rate of $91 \%$ for "opportunities to learn new technologies and applications." The inclusive and proactive value-driven nature of the industry-linked RIE pedagogy ensure that genderconstrained achievement is holistically addressed Shreffler, Shreffler \& Murfree, (2019). Furthermore, the project- and teaching-based RIE models of reflection (Ekpo, 2020) enable the learning and teaching stakeholders (Zaza, Harris, Arik \& Geho, 2019) to play vital productive roles that align with individualized achievements. Moreover, the analysed sample data reveal that $45 \%$ of the respondents chose their projects because of the embedded "rigour and technical depth of the project." It is obvious from the sampled data that $55 \%$ of the respondents favoured "future career prospects and professional practice" while choosing their individual research-informed engineering projects. Also, $55 \%$ of the respondents indicated that their research-informed project choice would be influenced strongly by the "availability and support of their supervisor." This is a question of engagement and attendance (Keyser, 2019) by the student and the supervisor. Though the student is the project manager and chief learner, the supervisor and teacher should be governed by a corresponding mechanism of engagement and attendance for a judicious progress evaluation. Hence, ensuring that the student projects reflect the core research activities and support resources within a Faculty promises to enhance the entrepreneurship, employability and employment of our graduates. Inclusive and proactive value-driven spontaneous and self-regulated learning occurs where the learners and teachers are co-knowledge creators and assimilators. Industrylinked pedagogy (Ekpo, 2020) eliminates prompted learning (Payne, 2019) and paves the way for individualized deeper learning Pereira \& Wahi, 2019). This would ensure that the relevant engineering competences would be built-up and enhanced for professional registration (including engineering chartership and incorporation). In terms of the number of time that the industry-linked FAFF tool is to be employed for curriculum/unit delivery and student project supervision, it depends on the deliverables of the project and the appropriate graduate-level skills that each activity requires. As a rule of thumb, the supervisor and the potential project students should be allowed to decide with recourse to the University's approved meetings threshold over the project duration. This study reveals that $100 \%$ of the students enjoyed the "regular individual and team meetings" where they discussed their works and achievements 
and exchange ideas with their peers in the presence of their supervisor. A key message that resounded in the questionnaire data is "I enjoyed the regular team meetings and quick responses to my emails by my supervisor." Hence, opportunities should be created for students to have their individual research projects pre-assessed by their peers for a feedback(s) with recourse to the assessment criteria of the University.

Furthermore, the results of the sample data analysis and simulations indicate that enhanced student engagement in an engineering project improves the achievements (including employability skills and good honours) of engineering students. The Monte Carlos simulations show that over $80 \%$ of the engineering students would favour research-informed student projects. Since over a million samples were utilised in the simulations, the analyses show that future student project experiences should be modelled after multidisciplinary research (that underpins the research activities within a research centre); peer-topeer engineering project team; and project-driven formative assessment and feedback (including mock presentations).

The positive impact benefits and/or outcomes achieved by implementing the proposed industry-linked RIE pedagogy include, but are not limited to, the following:

a) Real University-Industry alignment for future engineers;

b) Supervised UG \& MSc students work with University's industrial partners via:

i. Jobs for students;

ii. Industrial placement;

iii. Industry-linked knowledge transfer partnership;

iv. $\quad$ Sponsored PGR studentships - MRes/MPhil/PhD;

v. Industry linked research and development; and

vi. Contract research.

c) Technical publications with the students;

d) Contribution to the research excellence framework (REF) and the teaching excellence framework (TEF) metrics of the University.

The findings reveal that inclusive industry-linked research-informed-and-enriched curriculum enhances the student development and outcomes; academic career progress; professionalism; entrepreneurship; employment; and employability. The presented industry-linked research-informed-andenhanced pedagogy has the potential to attract established high-profile industry executives to support higher education as visiting professors (VPs). The Royal Academy of Engineering, UK promotes the VP roles and sponsors it at the UK Universities. Thus, this paper contains an established industry-linked learning and teaching enhancement evidence(s) that can drive higher education policy and regulation in the nearest future. The VP role fits nicely with the reported industry-linked RIE pedagogy benefits including industry-linked guest lecture; industry-linked specialist contents co-delivery; curriculum design; workshops and seminars; mentorship; industrial Visit; curriculum and units monitoring and improvements review; curricula and units delivery review; units assessments review and career talk; professional registration (e.g., CEng) advice; Faculty's industrial advisory board membership; and undergraduate and postgraduate projects supervision.

\section{CONCLUSION}

Students are passionate about learning new ideas, technologies and applications. Sustainability is achieved by using an established industry-linked RIE curriculum model to educate up-and-coming generations of engineering students; and prepare graduating engineering students to stay smart postgraduation. Industry-linked engineering pedagogy improves educational metrics significantly. Enhanced student engagement in an engineering project improves learners' achievements. Student project experiences should be modelled after multidisciplinary research that underpins the research activities within a research centre; and creates opportunities to learn new marketable skills.

In this paper, the impact of industry-linked engineering pedagogy has been investigated and presented. Formative assessments (with feedback and feedforward) trigger the implementation of reasonable learning and teaching intervention and adjustment strategies. From the advanced statistical and 
simulations data analyses, it is possible to predict the performance of a particular cohort of students and provide tailored inclusive support tutor-led tutorial sessions, peer-learning, lecture contents readjustments and unit topic revisions as parts of the intervention strategies. Approximately $90 \%$ of the project students indicate that they chose an engineering project and a supervisor respecting the opportunities to learn new technology and applications. The reported industry-linked research-informedand-enriched learning and teaching model and/or good practice can be extended to other units and courses across the University with appropriate adjustments. The findings reveal that integrated research-informedand-enriched model of reflection and formative assessment (with feedback and feedforward) is a productive teaching-supervision craft practice tool that promises to enhance the educational metrics of higher education institutions. The presented findings promise to inform potential institutional policies and/or regulations for excellent student experience, retention, progression and achievement.

\section{ACKNOWLEDGMENT}

The author thanks the Department of Engineering, Manchester Metropolitan University, UK for sponsoring this engineering pedagogy research project in order to enhance professional standard framework in higher education, advance educational metrics and boost teaching excellence.

\section{REFERENCES}

Argos, J., \& Ezquerr, P. (2014). Universities and skills for employability, Procedia - Social and Behavioral Sciences, 139, 290-296.

Black, P., \& William, D. (2009). Developing the Theory of Formative Assessment. Educational Assessment, Evaluation and Accountability (formerly: Journal of Personnel Evaluation in Education), 21(1), 5-31.

Ekpo, S. (2020). Industry-linked Projects and Research-informed-and-enriched Curriculum for Sustainable Student Employability Metrics. Proc. Advance HE STEM Conference (pp. 1-24). Manchester, UK,

Emerson, (2020). Solving the Challenge of a Growing Shortage of Engineering Expertise. A Machine Design Publication, pp. 1-23.

Felder, R., \& Silverman, L. (1988). Learning and Teaching Styles in Engineering Education. Engr. Education, 78(7), 674-681.

Felder, R., Woods, D., Stice, J., \& Rugarcia, A. (2000). The Future of Engineering Education II. Teaching Methods that Work. Chem. Engr. Education, 34(1), 26-39.

Fernando, M., \& Ekpo, S. (2015, March). A Review of Incorporating Live-Projects into Engineering Curriculum at the Manchester Metropolitan University. Proceedings of the 4th Cyprus International Conference on Educational Research (pp. 1-8). Kyrena, North Cyprus. Retrieved from http://www.awer-center.org/cyicer/.

Garrison, D. R., \& Kanuka, H. (2004). Blended Learning: Uncovering its Transformative Potential in Higher Education. The Internet and Higher Education, 7(2), 95-105.

Keyser, R. S. (2019). A Correlation Between Non-Mandatory Attendance and Course Grades in a FourthYear Hybrid Industrial Engineering Course. Journal of Higher Education Theory and Practice, 19(8), 17-22.

Moses, I. (1984). Supervision of Higher Degree Students - Problem Areas and Possible Solutions, Higher Education Research \& Development, 3(2), 153-165. DOI: 10.1080/0729436840030204

Nicol, D. J., \& MacFarlane-Dick, D. (2005). Formative assessment and self-regulated learning: A model and seven principles of good feedback practice. Studies in Higher Education, pp. 2-15.

Payne, A. (2019). Stepping Back to Let the Learning Happen: A Learning Practice in Higher Education. Journal of Higher Education Theory and Practice, 19(8), 39-44

Pereira, A. S., \& Wahi, M. M. (2019) Deeper Learning Methods and Modalities in Higher Education: A 20-year Review. Journal of Higher Education Theory and Practice, 19(8), 46-63.

70 Journal of Higher Education Theory and Practice Vol. 20(3) 2020 
Pintrich, P. R., \& Zusho, A. (2002). Student motivation and self-regulated learning in the college classroom. In J. C. Smart \& W.G. Tierney (Eds.), Higher Education: Handbook of Theory and Research (Volume XVII). New York: Agathon Press.

Popham, W. J. (2008). Transformative Assessment. Alexandria. Virginia: Association for Supervision and Curriculum Development.

Shreffler, M. B., Shreffler, J. R., \& Murfree, J. R. (2019). Barriers to Advancement of Female Faculty in Higher Education: An Examination of Student Evaluations of Teaching, Work-Family Conflict and Perceived Organizational Support. Journal of Higher Education Theory and Practice, 19(8), 72-83.

Zaza, S., Harris, A., Arik, M., \& Geho, P. (2019). The Roles Parents, Educators, Industry, Community, and Government Play in Growing and Sustaining the STEM Workforce. Journal of Higher Education Theory and Practice, 19(8), 114-127. 